\title{
В.Г. МАРТИНЕНКО
}

\section{КОМПЛЕКСНА ОЦНКА МЦНОСТІ КОМПОЗИЦЙНОЇ ЛОПАТКИ ВЕНТИЛЯТОРА ГОЛОВНОГО ПРОВІТРЮВАННЯ ШАХТИ}

Робота присвячена розробці та розрахункам міцності нового композиційного пера лопатки вентилятора головного провітрювання шахти, з поміж яких статичний та модальний аналізи, а також аналіз стійкості. При проведенні досліджень враховувались попередньо визначені аеродинамічні навантаження на бічну поверхню пера лопатки. Дослідження проводились за допомогою скінченно-елементного аналізу тонкостінної конструкції пера із застосуванням теорії товстих багатошарових оболонок. Оцінка статичної міцності виконувалась із застосуванням критерію міцності Хашина. Аналіз стійкості оболонки пера під дією згинних аеродинамічних навантажень проводився за допомогою методів лінійної теорії стійкості. Модальний аналіз виконувався із врахуванням переднапруженого стану від дії статичних навантажень. Аналіз результатів досліджень свідчить про достатню статичну та динамічну міцність композиційного пера та можливість його реалізації в реальній роторній машині при коректному проектуванні кріплення між металевою частиною хвоста лопатки та композиційним пером. Методика проектування та аналізу міцності композиційного пера лопатки вентилятора може бути застосована при створенні нових композиційних елементів турбомашин: коректний підбір товщин різних частин пера дозволяє прийти до равноміцної конструкції із раціональним використанням матеріалу; оптимальне розташування ребер жорсткості всередині оболонки пера дозволяє уникнути надмірних переміщень та напружень в ній і втрати нею стійкості, а також досягти максимальної відбудови від згинних власних частот коливань; запропонований комплексний підхід до оцінки міцності, що враховує дію аеродинамічних навантажень на перо лопатки при статичному аналізі та переднапружений стан при проведенні модального аналізу дозволяє значно підвищити точність та коректність розрахунків. Описаний в роботі підхід є новим для низькообертових роторних машин, оскільки на даний момент не існує комплексних методик до проектування композиційних лопаток вентиляторів та компресорів, а також відсутні згадування про конкретні приклади їхнього впровадження в реалізовані виробниками проекти.

Ключові слова: композиційний матеріал, лопатка вентилятора, міцність, стійкість, аеродинамічне навантаження.

Работа посвящена разработке и расчётам прочности нового композиционного пера лопатки вентилятора главного проветривания шахты, среди которых статический и модальный анализы, а также анализ устойчивости. При проведении исследований учитывались предварительно определённые аэродинамические нагрузки на боковую поверхность пера лопатки. Исследования проводились с помощью конечноэлементного анализа тонкостенной конструкции пера с применением теории толстых многослойных оболочек. Оценка статической прочности выполнялась с применением критерия прочности Хашина. Анализ устойчивости оболочки пера под действием изгибных аэродинамических нагрузок проводился с помощью методов линейной теории устойчивости. Модальный анализ выполнялся с учетом преднапряжённого состояния от действия статических нагрузок. Анализ результатов исследований свидетельствует о достаточной статическую и динамическую прочности композиционного пера и возможности его реализации в реальной роторной машине при корректном проектировании крепления между металлической частью хвоста лопатки и композиционным пером. Методика проектирования и анализа прочности композиционного пера лопатки вентилятора может быть применена при создании новых композиционных элементов турбомашин: корректный подбор толщины различных частей пера позволяет прийти к равнопрочной конструкции с рациональным использованием материала; оптимальное расположение ребер жестокости внутри оболочки пера позволяет избежать чрезмерных перемещений и напряжений в ней и потери ею устойчивости, а также достичь максимальной отстройки от изгибных собственных частот колебаний; предложенный комплексный подход к оценке прочности, учитывающий действие аэродинамических нагрузок на перо лопатки при статическом анализе и преднапряжённое состояние при проведении модального анализа позволяет значительно повысить точность и корректность расчётов. Описанный в работе подход является новым для низкооборотистых машин, поскольку на данный момент не существует комплексных методик по проектированию композиционных лопаток вентиляторов и компрессоров, а также отсутствуют упоминания о конкретных примерах их внедрения в реализованные производителями проекты.

Ключевые слова: композиционный материал, лопатка вентилятора, прочность, устойчивость, аэродинамическое нагружение.

The work is devoted to the development and calculation of the strength of a new composite fan blade of the main ventilation of the mine, including the static and modal analyzes, as well as the stability analysis. The studies took into account the pre-determined aerodynamic loads on the lateral surface of the blade airfoil. The research was carried out by means of the finite element analysis of the thin-walled airfoil structure using the theory of thick multilayer shells. Estimation of the static strength was performed using the Hashin strength criterion. Analysis of the airfoil shell buckling resistance under the action of bending aerodynamic loads was performed using the methods of the linear stability theory. The modal analysis was performed taking into account the prestressed state from the action of static loads. The analysis of the research results testifies to the sufficient static and dynamic strength of the composite airfoil and the possibility of its implementation in a real rotary machine with the correct design of the fastening between the metal part of the blade root and the composite airfoil. The method of designing and analyzing the strength of the fan blade composite airfoil can be used to create new composite elements of turbomachines: the correct selection of thicknesses of different parts of the airfoil allows obtaining a uniform design with rational use of material; the optimal location of the stiffeners inside the airfoil shell avoids its excessive displacement and stress and the buckling effects, as well as achieving the maximal detuning level from the bending natural frequencies of vibrations; the proposed integrated approach to the strength assessment, which takes into account the effect of aerodynamic loads on the blade airfoil in the static analysis and the prestressed state during the modal analysis can significantly improve the accuracy and correctness of calculations. The approach described in the paper is new for low-speed rotary machines, as at present there are no comprehensive methods for designing composite blades of fans and compressors, and there is no mention of specific examples of their implementation in the projects implemented by manufacturers.

Keywords: composite material; fan blade; strength; buckling resistance; aerodynamic loading.

Вступ. Використання композиційних матеріалів при виготовленні конструкційних елементів роторних машин є привабливою, але разом із тим й складною науково-технічною проблемою для вчених та інженерів. 3 одного боку, застосування композитів до високонавантажених машин дає великий виграш за рахунок їхньої порівняно низької щільності та високої міцності, що вкрай важливо при дії на такі елементи інерційних відцентрових сил, а 3 іншого боку, воно обмежується високою ціною та складністю виготовлення композиційних елементів конструкцій i машин, а також нетривіальністю проектування та розрахунків міцності цих елементів. В багатьох випадках тільки варіювання кількістю й матеріалом 
шарів композиту в різних місцях лопатки роторної машини та спрямованістю волокон в конкретному шарі дозволяють отримати міцну, але разом із тим легку композиційну структуру [1]. Наприклад, в [2] наведена пов'язана аеродинамічно-міцнісна оптимізація лопаті вітрогенератору із підбором товщин конструкції, орієнтації волокон композиту та його властивостей для досягнення оптимального сполучення міцнісних та вагових характеристик. Аналогічний процес оптимізації для досягнення мінімальної маси лопаті вітряної турбіни при збереженні іï міцності представлений в роботах [3], а в [4] оптимізація виконується шляхом проведення серії динамічних структурних аналізів. В статті [5] розглядаються різні режими навантаження лопаті для дослідження iii надійності. Пов'язані аеропружні коливання лопаті розглядаються в роботі [6]. В роботі [7] наводяться розрахунки міцності лопаті, що порівнюються із результатами експерименту.

Також композиційні матеріали використовуються для створення лопатей гелікоптерів [8] та двигунів морських судів [9]. Застосування композиційних матеріалів для виготовлення лопаток вентиляторів $є$ дуже обмеженим. Зазвичай вони використовуються при виробництві надлегких лопаток вентиляторних ступенів турбореактивних двигунів. Наприклад, в роботі [10] описаний процес створення композиційних лопаток, корпусу та спрямляючого апарату турбореактивного двигуна. В [11] наведені переваги від використання композиційних лопаток із змінним кутом атаки в турбореактивних двигунах. В статті [12] представлені розрахунки динаміки та міцності композиційної лопатки вентиляторного ступеня двигуна, що проектується. Як видно 3 огляду літератури, композиційні матеріали активно використовуються для виробництва лопаток роторних машин, але зазвичай це знаходить свою реалізацію у склопластикових лопатях вітрових турбін, де питання мінімальної маси конструктивних елементів стоїть дуже гостро через великі розміри машини (лопаті вітрогенераторів можуть досягати 150 метрів у довжину). В даній роботі пропонується застосування композиційного матеріалу до виготовлення пера лопатки вентилятора головного провітрювання шахти iз визначенням його міцності, що $\epsilon$ актуальною задачею з огляду на згадані особливості композитів.

\section{1. Розрахунок аеродинамічних навантажень на} лопатку. Вентилятор, для якого проектується композиційна лопатка, $\epsilon$ осьовим вентилятором головного провітрювання шахти. Комплексне дослідження його статичної та динамічної міцності для алюмінієвих та сталево-алюмінієвих лопаток було наведено в роботах [13-14]. Він призначений для обертання на швидкості 750 обертів за хвилину. Розрахунок показаних на рисунку 1 у поперечному перерізі аеродинамічних навантажень на бічну поверхню пера лопатки вентилятора разом із пов'язаним аеродинамічно-міцнісним аналізом були представлені в роботі [13]. При обчисленнях аеродинамічних навантажень враховувався вплив направляючого (зліва на рисунку) та спрямляючого (справа на рисунку) апаратів на аеродинамічний стан робочої лопатки (посередині).

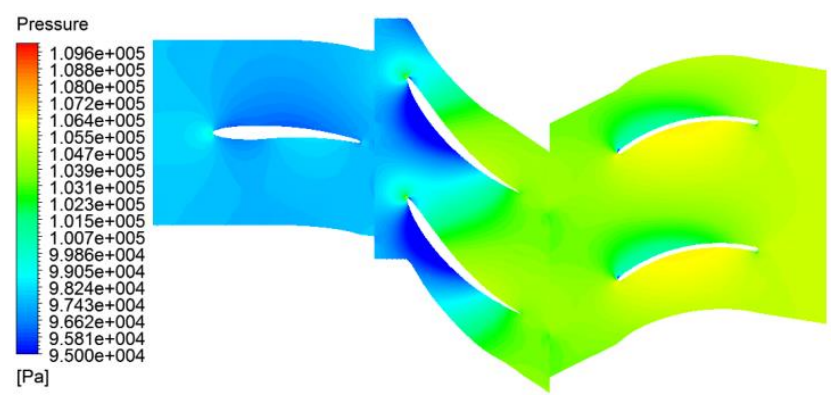

Рис. 1 - Аеродинамічне навантаження на перо лопатки (тиск повітря в проточній частині, [Па])

2. Структура композиційного пера лопатки. Матеріалом композиційного пера лопатки осьового вентилятора виступає склопластик «Ероху E-Glass UD» [15] у формі чотиришарового сандвічу товщиною $0,2[\mathrm{MM}]$ iз стандартною схемою плетіння [0\% $\left./ 45^{\circ} / 45^{\circ} / 90^{\circ}\right]$. В залежності від місця розташування на пері кінцева оболонка складається із різної кількості таких сандвічів, що показано на рис. 2.

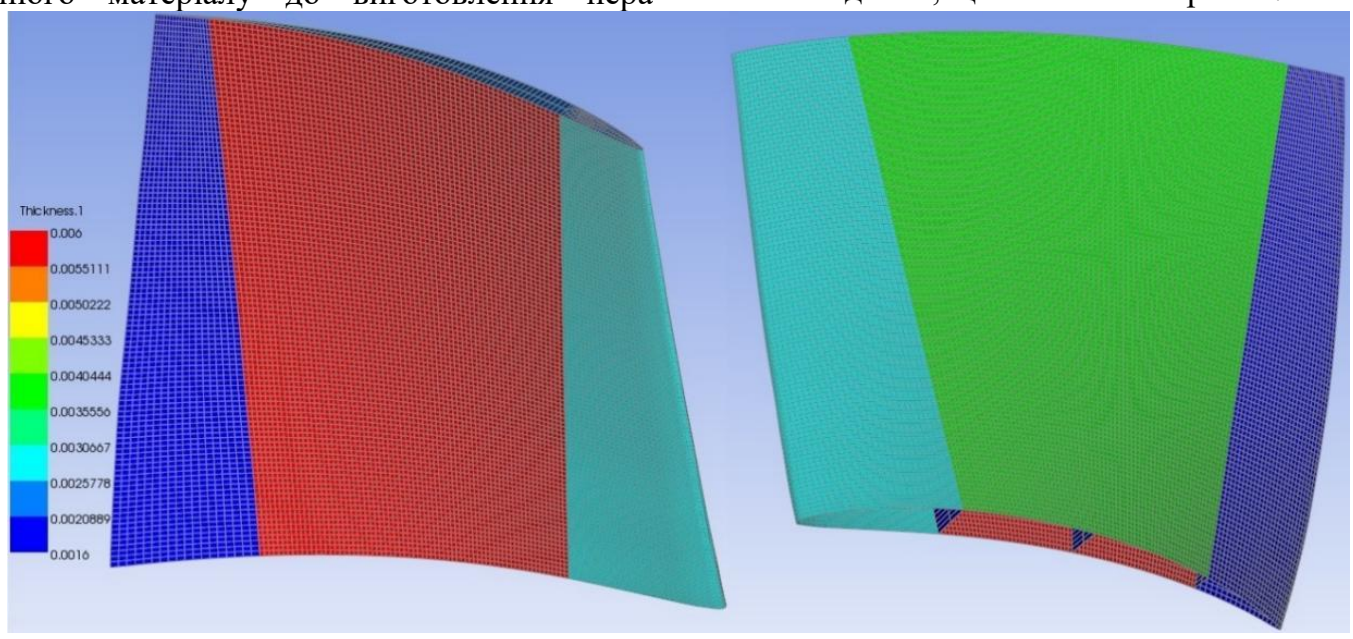

Рис. 2 - Загальний вид елементів композиційного пера лопатки із зазначенням товщини, [м] 
Також всередині оболонки вздовж радіального напрямку розташовані три ребра жорсткості, що спрямовані на протидію аеродинамічним навантаженням на перо лопатки та відбудову від згинних власних форм коливань. Фіксація пера лопатки із її сталевим хвостом передбачена по усьому нижньому торцю пера. Зважаючи на значно більшу жорсткість сталі у порівнянні із композиційним матеріалом, для розрахунків міцності пера фіксація вважається повністю жорсткою.

Статичними навантаженнями на перо лопатки у розрахунках виступають відцентрова сила при швидкості обертання 750 [об/хв] та різниця між робочим тиском на поверхні пера лопатки при протіканні навколо неї повітря та атмосферним тиском, яка прикладається до цієї поверхні.

\section{3. Оцінка статичної міцності композиційного} пера лопатки. Усі міцнісні розрахунки проводились за допомогою скінченно-елементних пакетів інженерного аналізу із застосуванням теорії товстих багатошарових оболонок. На рис. 3 представлений контурний графік сумарних переміщень, тобто середньоквадратичного значення координатних переміщень пера лопатки,

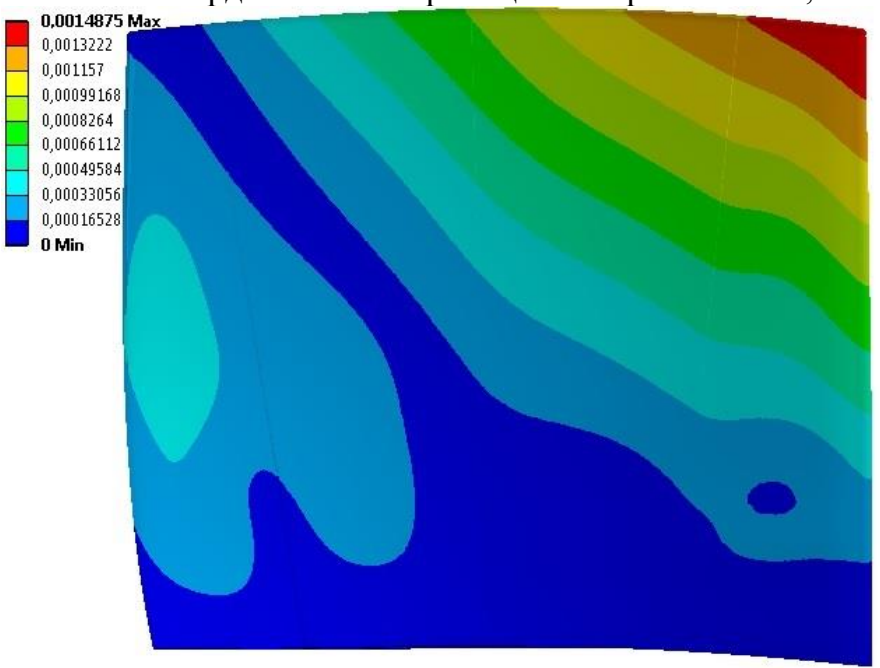

внаслідок аналізу якого встановлено, що максимальні переміщення воно має у верхній його частині зі сторони вхідної кромки. Значення максимального переміщення складає приблизно 1,5 [мм], що є меншим за зазор між лопаткою та корпусом, який становить 4 [мм], та не впливає на аеродинамічні характеристики профілю.

Як відомо, для оцінки міцності композиційних конструкцій застосовуються спеціально розроблені для них критерії міцності. Хашин в роботі [16] запропонував критерій міцності односпрямованих шарів армованих композитів. Як витікає зі згаданої роботи та проведених досліджень міцності склопластику, для випадку, що розглядається, достатньо застосовувати двовимірний критерій Хашина. На рис. 4 показаний розподіл функції критерію міцності на поверхні лопатки. Максимальне значення даної функції досягається в місці жорсткого закріплення пера лопатки та становить приблизно 0,52. Оскільки композиційний матеріал вважається міцним iз відповідним запасом у тому випадку, коли функція запасу міцності не перевищує значення 1, можна зробити висновок про достатню міцність розробленого композиційного пера лопатки.

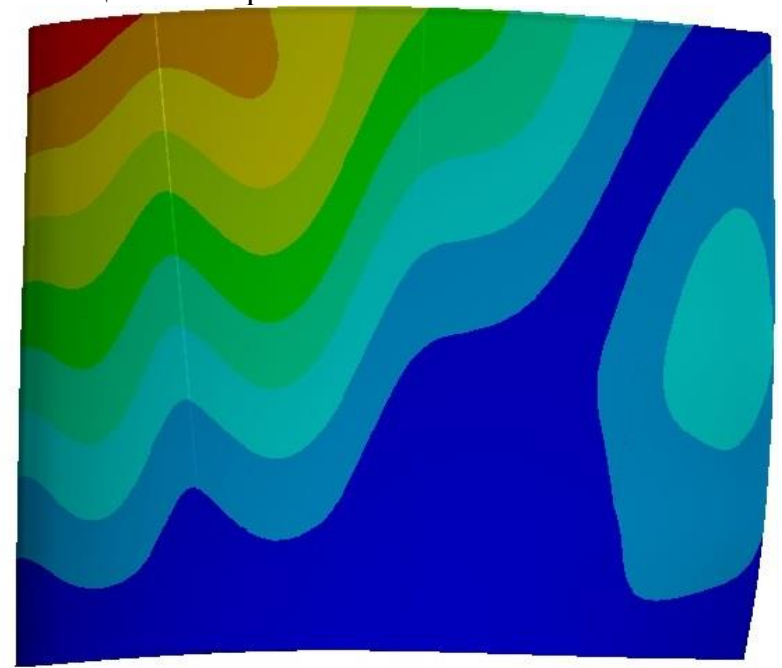

Рис. 3 - Контурний графік сумарних переміщень пера лопатки, [м]

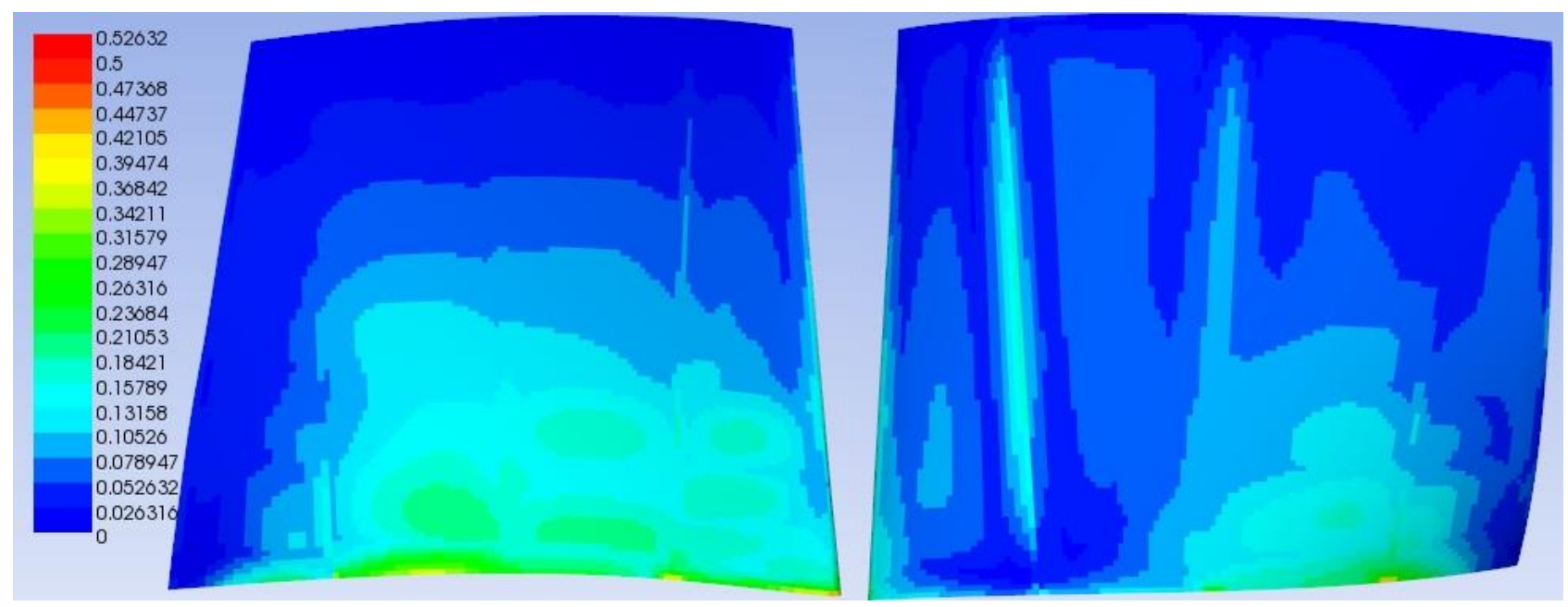

Рис. 4 - Контурний графік розподілу функції критерію міцності Хашина у пері лопатки, [-] 
4. Визначення стійкості композиційного пера під дісю аеродинамічних навантажень. 3 метою контролю стійкості оболонки під дією згинних аеродинамічних навантажень був проведений відповідний аналіз стійкості із врахуванням переднапруженого стану від дії статичних навантажень. 3 його допомогою було визначено, що коефіцієнт першого критичного навантаження на перо лопатки складає 22,64, тобто для втрати стійкості пером лопатки за першою формою прикладені навантаження повинні перевищувати робочі приблизно у 23 рази. При цьому перша форма втрати стійкості викликає вигин оболонки у хвостовій секції пера лопатки, тобто біля ії̈ вихідної кромки. Зважаючи на такий результат, подальший розгляд стійкості композиційного пера лопатки не проводився, оскільки воно, безсумнівно, є стійким.

5. Модальний аналіз композиційного пера лопатки. Для визначення вібраційних характеристик композиційного пера був проведений його модальний аналіз із врахуванням переднапруженого стану від дії статичних навантажень. При цьому рівень відбудови власних частот коливань пера від кратностей частоти збуджуючого навантаження визначався за формулою: $\Delta f_{i j}=\left[\left(f_{i}-j^{*} v\right) / v\right]^{*} 100 \%$, де $i-$ номер власної частоти; $j$ - кратність частоти збуджуючого навантаження; $\Delta f_{i j}$ запас відбудови; $f_{i}$ - власна частота коливань лопатки,
[Гц]; $v=n / 60$ - частота збудження, [Гц]; $n$ - швидкість обертання, [об/хв].

У відповідності до прийнятих стандартів достатнім рівнем відбудови можна вважати значення 20 \%. В таблиці 1 наведені рівні відбудови перших шести власних частот від перших шести кратностей збуджуючого навантаження, що відповідає швидкості обертання 750 [об/хв], а на рис. 5 показані відповідні їм власні форми коливань пера.
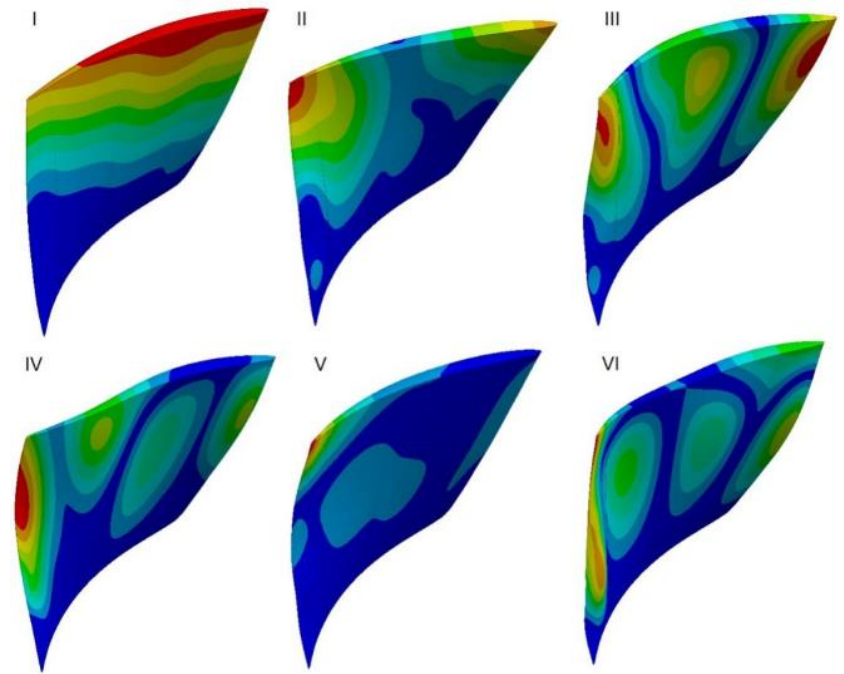

Рис. 5 - Власні форми коливань пера лопатки

Таблиця 1 - Рівень відбудови власних частот (ВЧ) композиційного пера лопатки

\begin{tabular}{|l|l|l|l|l|l|l|c|}
\hline \multirow{2}{*}{ № ВЧ } & \multirow{2}{*}{ Значення ВЧ, [Гц] } & \multicolumn{5}{|c|}{ Відносна відбудова ВЧ від кратностей частоти збуджуючого навантаження (КЧЗН), \% } \\
\cline { 3 - 8 } & & $1 \mathrm{KЧЗН}$ & 2 КЧЗН & 3 КЧЗН & 4 КЧЗН & 5 КЧЗН & 6 КЧЗН \\
\hline 1 & 120,36 & 862,88 & 762,88 & 662,88 & 562,88 & 462,88 & 362,88 \\
\hline 2 & 217,69 & 1641,52 & 1541,52 & 1441,52 & 1341,52 & 1241,52 & 1141,52 \\
\hline 3 & 285,93 & 2187,44 & 2087,44 & 1987,44 & 1887,44 & 1787,44 & 1687,44 \\
\hline 4 & 312,91 & 2403,28 & 2303,28 & 2203,28 & 2103,28 & 2003,28 & 1903,28 \\
\hline 5 & 334,57 & 2576,56 & 2476,56 & 2376,56 & 2276,56 & 2176,56 & 2076,56 \\
\hline 6 & 369,10 & 2852,80 & 2752,80 & 2652,80 & 2552,80 & 2452,80 & 2352,80 \\
\hline
\end{tabular}

Як видно з таблиці, навіть для першої власної частоти композиційного пера лопатки ії відбудова від шостої кратності $€$ більшою за $350 \%$, що дає можливість вважати розроблену конструкцію пера задовільної з точки зору його вібраційних якостей.

Висновки. Матеріалом спроектованого пера лопатки вентилятора головного провітрювання шахт виступає односпрямований склопластик, який $\epsilon$ дешевим та поширеним композиційним матеріалом й, окрім того, технологічним на етапі виготовлення деталі. Не дивлячись на його порівняно із іншими композитами низькі міцнісні та жорсткісні характеристики, завдяки вдалому поєднанню різних товщин бічної поверхні пера та додавання в нього внутрішніх ребер жорсткості вдалось досягти високих показників міцності, стійкості та надійності. В ході комплексного структурного аналізу композиційного пера лопатки вентилятора були проведені розрахунки аеродинамічних навантажень на перо, оцінка його статичної міцності, аналіз стійкості композиційної оболонки під дією тиску повітря, а також знайдені власні частоти та форми коливань конструкції, що розглядається. Цей комплексний підхід дозволив всебічно оцінити застосовність такої композиційної конструкцій при виготовленні лопаток низькообертових машин. Подальші розрахунки міцності та надійності доцільно проводити при аналізі усієї конструкції ротора в зборі, що ускладнить задачу та потребує створення додаткових методик.

\section{Список літератури}

1. Chortis D.I. Structural analysis of composite wind turbine blades / D.I. Chortis. - Springer, 2013. - 239 p.

2. Chen J. Structural optimization study of composite wind turbine blade / J. Chen, Q. Wang, W.Zh. Shen, X. Pang, S. Li, X. Guo // Materials and Design. - 2013. - vol. 46. - P. 247-255. https://doi.org/10.1016/j.matdes.2012.10.036

3. Monte A.D. Multi-objective structural optimization of a HAWT composite blade / A.D. Monte, M.R. Castelli, E. Benini // Composite Structures. - 2013. - vol.106. - P. 362-373. https://doi.org/10.1016/j.compstruct.2013.05.038 
4. Song $F$. Optimization design, modeling and dynamic analysis for composite wind turbine blade / F. Song, Y. Ni, Zh. Tan // Procedia $\begin{array}{lllll}\text { Engineering. } & - & 2011 . \quad-\quad \text { vol. 16, P. 369-375 }\end{array}$ https://doi.org/10.1016/j.proeng.2011.08.1097

5. Kong C. Structural investigation of composite wind turbine blade considering various load cases and fatigue life / C. Kong, J. Bang, Y. Sugiyama // Energy. - 2005. - vol. 30. - P. 2101-2114. https://doi.org/10.1016/j.energy.2004.08.016

6. Rafiee $R$. Simulation of aeroelastic behavior in a composite wind turbine blade / R. Rafiee, M. Tahani, M. Moradi // Journal of Wind Engineering and Industrial Aerodynamics. - 2016. - vol. 151. - P. 6069. https://doi.org/10.1016/j.jweia.2016.01.010

7. Yang $J$. Structural investigation of composite wind turbine blade considering structural collapse in full-scale static tests / J. Yang, Ch. Peng, J. Xiao, J. Zeng, S. Xing, J. Jin, H. Deng // Composite

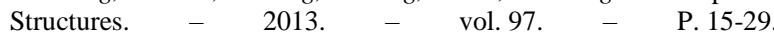
https://doi.org/10.1016/j.compstruct.2012.10.055

8. Garinis D. Dynamic analysis of modified composite helicopter blade / D. Garinis, M. Dinulović M., Rašuo B. // FME Transactions. - 2012 - vol. 40. - P. 63-68.

9. Lin H.J. Strength evaluation of a composite marine propeller blade / H.J. Lin, J.J. Lin, T.J. Chuang // Journal of reinforced plastics and composites. - 2005. - vol. 40(5). - P. 1791-1807. https://doi.org/10.1177/0731684405052199

10. Murakami T. Development of composite fan system / T. Murakami, H. Morita, K. Oikawa // IHI Engineering Review. - 2014. vol. 47(1). - P. 57-61.

11. Mazzawy R.S. Performance study for benefits of variable pitch composite fan / R.S. Mazzawy // Proceedings of ASME Turbo Expo 2010: Power for Land, Sea and Air. -Glasgow, 2010. - P. 1-9. https://doi.org/10.1115/GT2010-22148

12. Coroneos R.M. Structural analysis and optimization of a composite fan blade for future aircraft engine / R.M. Coroneos, R.S.R. Gorla // International Journal of Turbojet Engines. - 2012. - vol. 29(3). P. 131-164. https://doi.org/10.1515/tjj-2012-0024

13. Мартыненко В.Г. Анализ статической и динамической прочности осевого вентилятора с учётом аэродинамических свойств потока и неоднородности температурного поля В.Г. Мартыненко, Н.И. Гриценко // Проблемы машиностроения. - 2015. - Т. 18, № 4/1. - С. 44-52.

14. Мартиненко В.Г. Проектування, аналіз та експериментальне дослідження статичної міцності композиційної біметалічної лопатки вентилятора головного провітрювання шахти / В.Г. Мартиненко, М.І. Гриценко, С.В.Мавродій // Вісник Національного технічного університету «ХПІ». Серія: Динаміка та міцність машин. - 2018. - № 38 (1314). - С. 20-31. https://doi.org/10.20998/2078-9130.2018.38.152477

15. Sai Ashok $M$. Failure analysis of unidirectional composite pinnedjoints / M. Sai Ashok, U. Koteswara Rao // International Journal of Engineering Development and Research. - 2017. - vol. 5(4). P. 139-147.

16. Hashin Z. A fatigue criterion for fiber-reinforced materials Z. Hashin, A. Rotem // Journal of Composite Materials. - 1973. vol. 7. - P. 448-464. https://doi.org/10.1177/002199837300700404

\section{References (transliterated)}

1. Chortis D.I. Structural Analysis of Composite Wind Turbine Blades Springer, 2013. $239 \mathrm{p}$
2. Chen J., Wang Q., Shen W.Zh., Pang X., Li S., Guo X. Structural optimization study of composite wind turbine blade. Materials and Design. 2013, vol. 46, pp. 247-255.

3. Monte A.D., Castelli M.R., Benini E. Multi-objective structural optimization of a HAWT composite blade. Composite Structures, 2013, vol. 106. pp. 362-373.

4. Song F., Ni Y., Tan Zh. Optimization design, modeling and dynamic analysis for composite wind turbine blade. Procedia Engineering, 2011, vol. 16, pp. 369-375.

5. Kong C., Bang J., Sugiyama Y. Structural investigation of composite wind turbine blade considering various load cases and fatigue life. Energy, 2005, vol. 30, pp. 2101-2114.

6. Rafiee R., Tahani M., Moradi M. Simulation of aeroelastic behavior in a composite wind turbine blade. Journal of Wind Engineering and Industrial Aerodynamics, 2016, vol. 151, pp. 60-69.

7. Yang J., Peng Ch., Xiao J., Zeng J., Xing S., Jin J., Deng H. Structural investigation of composite wind turbine blade considering structural collapse in full-scale static tests. Composite Structures, 2013, vol. 97, pp. 15-29.

8. Garinis D., Dinulović M., Rašuo B. Dynamic analysis of modified composite helicopter blade. FME Transactions, 2012, vol. 40, pp. 63 68.

9. Lin H.J., Lin J.J., Chuang T.J. Strength evaluation of a composite marine propeller blade. Journal of Reinforced Plastics and Composites, 2005, vol. 40, no. 5, pp. 1791-1807.

10. Murakami T., Morita H., Oikawa K. Development of composite fan system. IHI Engineering Review, 2014, vol. 47, no. 1, pp. 57-61.

11. Mazzawy R.S. Performance study for benefits of variable pitch composite fan. Proceedings of ASME Turbo Expo 2010: Power for Land, Sea and Air. Glasgow, 2010, pp. 1-9.

12. Coroneos R.M., Gorla R.S.R. Structural analysis and optimization of a composite fan blade for future aircraft engine. International Journal of Turbojet Engines, 2012, vol. 29, no. 3, pp. 131-164.

13. Martynenko V.G., Hrytsenko N.I. Analiz staticheskoy i dinamicheskoy prochnosti osevogo ventilyatora $\mathrm{s}$ uchotom aerodinamicheskikh svoystv potoka i neodnorodnosti temperaturnogo polya [Analysis of the static and dynamic strength of an axial fan, taking into account the aerodynamic properties of the flow and the heterogeneity of the temperature field]. Problemy mashinostroyeniya [Problems of machine building]. 2015, vol. 18, no. 4/1, pp. 44-52. Available at http://journals.uran.ua/jme/article/view/57509 (accessed 13.11.2018).

14. Martynenko V.G., Hrytsenko N.I., Mavrody S.V. Proektuvannya, analiz ta eksperymental'ne doslidzhennya statychnoyi mitsnosti kompozytsiynoyi bimetalichnoyi lopatky ventylyatora holovnoho provitryuvannya shakhty [Design, analysis and experimental study of static strength of composite bimetal blade of mine main ventilation fan]. Visnyk NTU "KhPI" [Bulletin of the National Technical University "KhPI"]. Kharkov, NTU "KhPI" Publ., 2018, no. 38 (1314), pp. 20-31.

15. Sai Ashok M., Koteswara Rao U. Failure analysis of unidirectional composite pinned-joints. International Journal of Engineering Development and Research, 2017, vol. 5, no. 4, pp. 139-147.

16. Hashin Z., Rotem A. A fatigue criterion for fiber-reinforced materials. Journal of Composite Materials, 1973, vol. 7. pp. 448-464.

Надійшла (received) 29.05.2021

\section{Відомості про авторів / Сведения об авторах / About the Authors}

Мартиненко Володимир Геннадійович - кандидат технічних наук, Національний технічний університет «Харківський політехнічний інститут», старший науковий співробітник кафедри Динаміки та міцності машин; м. Харків; тел.: (057) 707-68-79; e-mail: martynenko.volodymyr@gmail.com; ORCID: https://orcid.org/0000-00029471-0905.

Мартыненко Владимир Геннадьевич - кандидат технических наук, Национальный технический университет «Харьковский политехнический институт», старший научный сотрудник кафедры Динамики и прочности машин; г. Харьков; тел.: (057) 707-68-79; e-mail: martynenko.volodymyr@gmail.com; ORCID: https://orcid.org/0000-0002-9471-0905.

Martynenko Volodymyr Gennadiyovych - Candidate of Technical Science, National Technical University "Kharkiv Polytechnic Institute", Senior research fellow of the Dynamic and Strength of Machines Department; Kharkiv; phone: (057) 707-68-79; e-mail: martynenko.volodymyr@gmail.com; ORCID: https://orcid.org/0000-0002-9471-0905. 